\title{
Legislação acessível em tempos de pandemia: a extensão como instrumento de conscientização e emancipação
}

\section{Accessible legislation in times of pandemic: extension as an instrument of awareness and emancipation}

\author{
João Eudes da Silva ${ }^{1 *}$, Camila Bernardino de Oliveira Lamas, Sara Elizabeth da Silveira, Naiara \\ Costa Vidigal, Michael Cassemiro de Carvalho, Kelven Correa de Paula e Gisely de Souza \\ Gomes
}

\begin{abstract}
RESUMO
O presente trabalho apresenta o relato de experiência acerca do projeto de extensão intitulado "Legislação Acessível em Tempos de Pandemia”, cujo escopo foi produzir e oferecer à comunidade do município de Rio Pomba e região, entre os meses de abril e novembro de 2020, material explicativo e de fácil compreensão sobre as legislações aprovadas neste período de pandemia, sobretudo aquelas destinadas a regular as relações trabalhistas e as relativas a auxílios financeiros à população. A partir do desenvolvimento do projeto de extensão citado e de seu significativo alcance, identificou-se que a educação jurídica, socializada através de conteúdos simples e didáticos, se mostrou de suma importância, sobretudo à população em geral. Como resultados, destacam-se, no que tange aos estudantes, o desenvolvimento do seu protagonismo, engajamento e postura ativa diante de problemas sociais. Lado outro, para a comunidade destinatária das ações e do conteúdo produzido, foi possível conhecer seus direitos e as ações implementadas para o enfrentamento do estado de calamidade pública e, com isso, exercer a cidadania de forma plena e consciente.
\end{abstract}

Palavras-chave: Alterações legislativas; Interpretação jurídica; Auxílio financeiro; Mídias sociais.

\begin{abstract}
"Accessible Legislation in Times of Pandemic", whose scope was to produce and offer material to the community of the Rio Pomba City and region, between the months of April and November 2020, material explanatory and easy to understand on the legislation passed during this period of pandemic, especially those aimed at regulating labor relations and those relating to financial aid to the population. Therefore, it presents the methodology used in the execution of the project and each of the materials developed, in addition to the results obtained through the action, with emphasis on the scope of socialization. From the development of such an extension project and its significant reach, it was identified that legal education, socialized through simple and didactic contents, proved to be of paramount importance, especially to the general population. As a result, regarding students, the development of their protagonism, engagement and active posture in the face of social problems stand out. On the other hand, for the community receiving the actions and the content produced, it was possible to know their rights and the actions implemented to face the state of public calamity and, with this, exercise citizenship in a full and conscious way.
\end{abstract}

Keywords: Legislative changes; Legal interpretation; Financial assistance; Social media.

\footnotetext{
${ }^{1}$ IF Sudeste MG - Campus Rio Pomba.

*joao.eudes@ifsudestemg.edu.br
} 


\section{INTRODUÇÃO}

Deslandes e Arantes (2017) descrevem a extensão universitária como “[...] um dos pilares do ensino superior no Brasil, que fomenta não somente a formação profissional e humanística, mas também a transformação social", reforçando, portanto, a importância da comunidade acadêmica para o desenvolvimento social.

Nesse contexto, destaca-se a relevância de ações que visem à proximidade entre o ambiente acadêmico e a sociedade, com ganhos para ambos os lados: para os estudantes, a oportunidade de desenvolverem o protagonismo e envolverem-se em soluções de problemas sociais; para a sociedade, por seu turno, a oportunidade de desenvolverem-se e aprimorarem suas ações a partir do conhecimento produzido na academia.

Sob essa perspectiva, conforme narram Lamas, Miranda e Oliveira (2018), o estudante precisa ser visto para além do mero papel de estudante, devendo ser considerada a integralidade de sua vida e os outros papéis que desempenha na esfera social, a fim de desenvolver-se em suas múltiplas dimensões. Nesse cenário, destaca-se a importância das práticas de extensão que possibilitam aos estudantes uma formação humanista.

Acerca disso, importa destacar ainda a necessidade e importância de práticas extensionistas que visem à divulgação e socialização da legislação vigente em nosso país, como forma de contribuir para a inclusão e o exercício pleno da cidadania por parte de seus destinatários, sobretudo em momentos de crise como a que estamos passando.

Assim, a partir do projeto extensionista "Legislação Acessível em Tempos de Pandemia", alvo do presente relato de experiência, a comunidade de Rio Pomba - MG e todo o público interessado no tema, passaram a receber sucessivos conteúdos informativos. O referido projeto focou na produção e divulgação de conteúdo de fácil entendimento sobre as novidades na legislação brasileira, durante parte do período da pandemia, principalmente de assuntos relacionados ao direito trabalhista e auxílios financeiros disponibilizados pelo governo para empresas e população.

A ação se justificou, sobretudo, em razão das constantes alterações legislativas nas áreas supramencionadas, em razão dos enormes impactos econômicos advindos da pandemia do coronavírus (COVID-19). A população de modo geral, assim como os pequenos empregadores, precisava ter acesso à referida legislação e compreendê-la 
adequadamente, o que se apresenta como fundamental em um momento em que as decisões precisavam ser tomadas com urgência e acerto.

Toda a veiculação dos materiais produzidos pelos estudantes dos cursos de Direito e Administração do Instituto Federal do Sudeste de Minas Gerais - Campus Rio Pomba foi feita a partir das mídias sociais, sobretudo em plataformas como Facebook e Instagram, nos perfis do curso de Direito e nos canais sociais da Instituição (site, Facebook e Instagram).

Conforme afirmam Alves, Silva, Ferreira e Lima (2020), "a inserção de tecnologias digitais à prática educativa é uma demanda central das sociedades contemporâneas" e "o potencial formativo das atividades de ensino, pesquisa e extensão fora do currículo formal pode contribuir significativamente para este processo".

Destarte, o presente trabalho relata a experiência do grupo de discentes ao desenvolver um projeto de extensão sobre a prática de produzir, a partir da orientação de seus professores, conteúdo explicativo e de fácil compreensão durante o isolamento social, recorrendo a tecnologias disponíveis e mídias digitais, procurando conscientizar a comunidade em relação às novas legislações aprovadas entre abril e novembro de $2020 \mathrm{e}$ legitimar, por meio da extensão universitária, o protagonismo e a função social do discente diante de um estado de calamidade pública.

\section{METODOLOGIA}

Apesar de disseminado pelas redes sociais, o presente projeto desenvolvido pelos estudantes dos cursos de Direito e Administração do Campus Rio Pomba do IF Sudeste MG elegeu como público principal a população do município de Rio Pomba, as cidades circunvizinhas e as pequenas e médias empresas da região. Já a finalidade do projeto foi estudar, conhecer e difundir as legislações junto à comunidade. Para a realização do trabalho, focou-se na elaboração de conteúdo que possuísse uma linguagem simples e de fácil entendimento, partindo do princípio de que parte do público é leiga em relação à temática jurídica.

Conforme afirma Zambon (2014), é tarefa da comunidade escolar contribuir para a formação de cidadãos para atuar e tornar a sociedade mais democrática, o que inclui fomentar - lhes a consciência dos seus direitos e deveres, para que apresentem postura crítica diante dos problemas sociais e engajamento na resolução dos mesmos. 
A produção dos conteúdos que posteriormente foram divulgados para a sociedade foi precedida de um planejamento do assunto a ser abordado, criação de um grupo de estudos e a divisão de dois subgrupos para a realização das tarefas preestabelecidas. Todos os integrantes, estudantes dos cursos de Direito e Administração, participaram de reuniões semanais, que aconteciam via online com a presença dos docentes orientadores do projeto, nas quais eram abordados e estudados os assuntos que subsidiaram a produção do material para sua posterior veiculação.

Após a identificação e definição das informações que seriam socializadas, dando ênfase aos conteúdos de maior importância para o conhecimento da comunidade, o primeiro subgrupo de estudantes se dedicava à elaboração da escrita do material, atentando-se para a produção de um texto sucinto, didático e de fácil compreensão, acerca das novas legislações e alterações legislativas trabalhista e econômica sucessivamente decretadas e sancionadas durante o período da pandemia.

Ao segundo subgrupo de estudantes coube desenvolver a arte e a estratégia de divulgação da matéria produzida por meio de vídeos, banners, cartilhas e infográficos. Este subgrupo ficou responsável ainda pelo acompanhamento do feedback, a partir do levantamento de dados relacionados ao alcance das divulgações realizadas e o quantitativo de downloads efetivados por parte do público.

Além disso, toda a equipe tratou de recolher as dúvidas suscitadas pela comunidade, que eram posteriormente discutidas e respondidas tempestivamente. Para a divulgação do material, a partir de uma arte visualmente atraente e com um texto curto e suficientemente didático, utilizou-se as redes sociais, sobretudo as plataformas da Instituição, do curso de bacharelado em Direito e aplicativos como o Whatsapp.

\section{RELATO DA EXPERIÊNCIA}

Desde o início as atividades do projeto foram desenvolvidas integralmente online. Assim, os dezesseis participantes e os dois docentes orientadores passaram a encontrarse frequentemente, promovendo discussões para se chegar ao formato ideal para a realização do projeto. Desta forma, os dezesseis alunos foram divididos em dois subgrupos: um pertencente à parte de conteúdo e o outro vinculado à parte gráfica, artística e de divulgação. 
O maior desafio para o subgrupo com atribuição referente à elaboração de conteúdo foi elaborar um texto simplificado, que atingisse o interesse e a compreensão da população leiga. Ao subgrupo da parte gráfica e artística coube enfrentar indubitavelmente seus primeiros desafios: estabelecer os posts com marcos identitários do projeto.

Por outro lado, no que tange aos professores orientadores, estes enfrentaram vários entraves, dentre os quais destacam-se: separar conteúdo de interesse de forma célere, tendo em vista o alto índice de aprovação de legislação no período, manter a organização, garantir a entrega tempestiva por parte dos subgrupos, avaliar a qualidade das matérias e promover a correção final dos posts.

As postagens do conteúdo produzido foram feitas de forma semanal e disponibilizadas de acordo com o fluxo de informação mais recente. Em relação aos assuntos abordados, pode-se elencar: Lei $\mathrm{n}^{\mathrm{o}}$ 13.982: você conhece o auxílio emergencial?; Benefício de prestação continuada - LOAS; Medidas trabalhistas para enfrentamento do estado de calamidade pública - Parte 1; Medidas trabalhistas para enfrentamento do estado de calamidade pública - Parte 2; FGTS - situações que autorizam o saque; Manutenção da qualidade de segurado: período de graça no Regime Geral de Previdência Social; Direitos trabalhistas nas diversas modalidades de rescisão; Seguro desemprego: conheça as regras para recebimento; Lei Aldir Blanc: lei no 14.017 de 29 de junho de 2020; Ensino remoto emergencial: orientações sobre direitos autorais e de imagem; Lei $n^{\circ}$ 14.023: prioriza ações para preservação da saúde e vida dos profissionais essenciais no combate à pandemia; Prorrogação do auxílio emergencial; Lei $n^{\circ} 14.020$ e Decreto $n^{\circ}$ 14.422: medidas trabalhistas para o enfrentamento do estado de calamidade pública; Lei n 14.046 de 24 de agosto de 2020: conversão da MP 948/2020; Atualização - auxílio emergencial - 21/09; NOVO FIES; Regulamentação da idade da mãe adolescente para recebimento do auxílio emergencial (Decreto ${ }^{\circ}$ 10.398/2020); Prorrogação do auxílio emergencial (MP nº1.000/2020); Portaria conjunta $\mathrm{n}^{\mathrm{o}} 20$ de 18 de junho de 2020 - parte 1; Portaria conjunta $n^{\circ} 20$ de 18 de junho de 2020 - parte 2; Portaria conjunta $n^{\circ} 20$ de 18 de junho de 2020 - parte 3; Portaria conjunta $n^{\circ} 20$ de 18 de junho de 2020 - parte 4; Portaria conjunta $\mathrm{n}^{\mathrm{o}} 20$ de 18 de junho de 2020 - parte 5; Portaria conjunta $\mathrm{n}^{\circ} 20$ de 18 de junho de 2020 - parte 6; Portaria conjunta n 20 de 18 de junho de 2020 - parte 7; Vídeo da Medida Provisória 927; Vídeo da Lei n 23.643 de 22/05/2020 do Estado de Minas Gerais e Portaria ${ }^{\circ} 16.655$ de 14 de julho de 2020. 
Deve-se destacar que, com o fim de alavancar o dinamismo do projeto, diversificando o material e o tornando mais atraente e interativo, foram produzidos cartilhas, infográficos e vídeos de curta duração.

Como se tornaria um texto longo e exaustivo para narrar toda a produção realizada e, com o fim de elucidar, a título de exemplo, os critérios de escolha dos assuntos trabalhados, a forma de abordagem, a escolha do produto a ser confeccionado e o alcance obtido, segue uma síntese do trabalho produzido, com a descrição de algumas postagens e sua motivação. Ademais, todos os temas explorados, o tipo de produto confeccionado e a referência dos documentos consultados estão elencados no Quadro 1, o alcance dos conteúdos postados nas mídias sociais figura no Quadro 2 e todos os conteúdos produzidos podem ser acessados, na sua íntegra, a partir do endereço Legislação Acessível em Tempos de Pandemia ${ }^{1}$. Os Quadros 1 e 2 serão apresentados adiante, no final desta descrição.

O primeiro post, intitulado "Você conhece o Auxílio Emergencial?", foi criado em forma de cartilha, com cores vivas e uma disposição de leitura que atendesse à harmonia visual. O gênero "cartilha" foi escolhido para favorecer a capacidade visual e facilitar a distinção entre os elementos dispostos nas informações.

A temática do Auxílio Emergencial tornou-se assunto de grande relevância para a sociedade, considerando o momento de grande dificuldade pelo qual passava e ainda passa a população brasileira: perdas de contratos de trabalhos, afastamentos, maiores gastos com a saúde, entre outros. Apesar do Auxílio Emergencial ter sido implantado por um viés econômico, ele atingiu exponencialmente a esfera social. Diante disso, tornou-se salutar a elaboração de um material explicativo sobre o assunto, que representou o maior alcance do projeto, tendo, no Instagram, um alcance de 1.547 contas e 1.812 impressões e, no Facebook, um alcance de 1.682 contas e 1.947 impressões.

A cartilha de Benefício de Prestação Continuada (LOAS) desempenhou um papel muito relevante porque se trata de um benefício assistencial, prestado pelo Instituto Nacional de Seguridade Social (INSS). Segundo Gurgel (2020), “[...] com a pandemia, foi ampliada de $25 \%$ para $50 \%$ de um salário mínimo per capita a renda mínima necessária para recebimento do benefício, provendo um maior número de famílias" A postagem da referida cartilha recebeu significativa aceitação na rede social: no Instagram teve um alcance de 971 contas e 1.223 reações, enquanto no Facebook o alcance atingiu 1.023 contas e 1.162 impressões. 
A postagem, em duas etapas, do conteúdo intitulado As Medidas Trabalhistas para enfrentamento do estado de calamidade pública obteve a seguinte reação na mídia social: as duas partes postadas tiveram juntas no Instagram 2.115 em alcance de contas e 2.321 impressões. No Facebook, o alcance de contas atingiu 2.239 e 2.589 reações.

A Manutenção da qualidade de segurado: período de graça no Regime Geral de Previdência Social foi o sexto conteúdo produzido pelo projeto. O post relacionado abordou a Lei 8.213 de 24 de julho de 1991, que consagrou sistematicamente a funcionalidade do "período de graça". A população precisava ter ciência de que, mesmo não contribuindo com a Previdência Social, algo comum naquele período em razão dos altos índices de desemprego, caso o beneficiário necessitasse de algum benefício/auxílio previdenciário, ele teria direito a ele.

Para a cartilha sobre a "Lei Aldir Blanc: Lei no 14.017 de 29 de junho de 2020", devotada a todos os artistas, preocupou-se com a produção de um material de natureza plural, que apresentasse as disposições emergenciais auxiliadoras, abrangendo todo setor cultural. Como a referida Lei é composta por muitas excepcionalidades, tratar do assunto de forma didática foi um árduo desafio a ser trabalhado.

A "Prorrogação do Auxílio Emergencial" deu lugar à décima segunda postagem e foi efetivada a partir da Medida Provisória $n^{\circ} 1000$ de 2020. A referida legislação desempenhou um papel crucial para a população de baixa renda e, desse modo, foi de grande apelo ao público. Esta postagem obteve o segundo maior número de alcance e reações nas redes sociais, consagrando-se com um alcance de 2.753 contas e 3.313 reações.

O conteúdo "Lei $\mathrm{n}^{\circ} 14.020$ e Decreto 14.422: medidas trabalhistas para o enfrentamento do estado de calamidade pública" vinculou as legislações mencionadas às medidas que os trabalhadores tiveram de adotar devido à pandemia.

O conteúdo da Lei no 14.046 de 24 de agosto de 2020: conversão da MP 948/2020 explicou a notícia do cancelamento e adiamento dos serviços de setores da cultura e do turismo durante a pandemia. Na sequência, houve a necessidade da postagem de um material que informasse acerca da atualização do Auxílio Emergencial. Para tanto, foi postado o produto intitulado Atualização do Auxílio Emergencial.

No âmbito da educação, surgiu a Lei 13.998 de 14 de maio de 2020, que visou à suspensão das parcelas do FIES (Fundo de Financiamento Estudantil). Essa postagem atingiu um alcance de 674 contas e 746 reações no Instagram. No Facebook, o alcance 
foi muito significativo, revelando sua pertinência ao chegar aos números de 1.430 contas e 1.607 reações.

Ademais, a "Regulamentação da idade da mãe adolescente para recebimento do auxílio emergencial", por meio do Decreto $\mathrm{n}^{\circ} 10.398$ de 2020, foi outro assunto muito discutido, motivo pelo qual foi objeto de um material específico.

A Portaria Conjunta $\mathrm{n}^{\mathrm{o}} 20$ de 18 de junho de 2020 desdobrou-se em sete produtos, que foram elaborados e divulgados de forma sequencial. Nesse cenário, é interessante ressaltar a preocupação do projeto em não tornar o material maçante. Para tanto, foram elaboradas, atendendo ao mesmo assunto, diversificadas formas de abordagens, a saber: vídeos, infográficos e cartilhas.

A pandemia e o advento do isolamento, com as famílias muitas vezes reclusas em casa, motivaram a produção do conteúdo acerca da Lei nº 23.643 de 22 de maio de 2020 do Estado de Minas Gerais, que dispõe sobre a comunicação a órgãos de segurança pública de ocorrência, ou indício de ocorrência, de violência doméstica e familiar contra mulher, criança, adolescente ou idoso nos condomínios residenciais localizados no Estado.

O último material explorado foi a "Portaria n 16.655 de 14 de julho de 2020 ", de significativo apelo para a sociedade, visto que trata da hipótese de recontratação do trabalhador nos casos de rescisão sem justa causa, durante o estado de calamidade pública.

A principal fonte do arcabouço jurídico consultado para a execução de mais de 90\% do projeto foi o Portal da Legislação do Governo Federal ${ }^{2}$.

Apresenta-se, a seguir, o Quadro 1 elencando todos os temas explorados, o tipo de produto confeccionado e a referência dos documentos consultados.

Quadro 1. Resumo das produções oriundas do Projeto "Legislação Acessível em Tempos de Pandemia", onde se encontram elencados os temas explorados, o tipo de produto confeccionado e a referência dos documentos consultados.

\begin{tabular}{|c|c|c|}
\hline Tema & Produto & Referência \\
\hline $\begin{array}{l}\text { Você conhece o } \\
\text { Auxílio } \\
\text { Emergencial? }\end{array}$ & Cartilha & $\begin{array}{l}\text { Lei } 13.892 \text { de } 2 \text { de Abril de 2020. Disponível em: } \\
\text { https://www.in.gov.br/en/web/dou/-/lei-n-13.982-de-2-de-abril-de-2020- } \\
\text { 250915958. Acesso em 18/12/2020. Decreto 10.316 de } 7 \text { de Abril de } 2020 . \\
\text { Disponível em: http://www.planalto.gov.br/ccivil_03/_ato2019- } \\
\text { 2022/2020/decreto/d10316.htm. Disponível em 18/12/2020. }\end{array}$ \\
\hline $\begin{array}{l}\text { Requisição do } \\
\text { Benefício de } \\
\text { Prestação } \\
\text { Continuada } \\
\text { (BPC) }\end{array}$ & Cartilha & $\begin{array}{l}\text { Lei } 13.892 \text { de } 2 \text { de Abril de 2020. Disponível em: } \\
\text { http://www.planalto.gov.br/ccivil_03/_ato2019-2022/2020/lei/113982.htm. } \\
\text { Acesso em 18/12/2020. Lei 8.742 de } 2 \text { de Abril de 2020. Disponível em: } \\
\text { http://www.planalto.gov.br/ccivil_03/leis/18742.htm.Acesso em 18/12/2020. }\end{array}$ \\
\hline
\end{tabular}




\begin{tabular}{|c|c|c|}
\hline $\begin{array}{l}\text { Medidas } \\
\text { Trabalhistas para } \\
\text { o Enfrentamento } \\
\text { do Estado de } \\
\text { Calamidade } \\
\text { Pública - Parte } 1\end{array}$ & Cartilha & $\begin{array}{l}\text { Medida Provisória } 927 \text { de } 2020 \text {. Disponível em: } \\
\text { http://www.planalto.gov.br/ccivil_03/_ato2019-2022/2020/mpv/mpv927.htm. } \\
\text { Acesso em: 18/12/2020. }\end{array}$ \\
\hline $\begin{array}{l}\text { Medidas } \\
\text { Trabalhistas para } \\
\text { o Enfrentamento } \\
\text { de estado de } \\
\text { Calamidade } \\
\text { Pública- Parte } 2\end{array}$ & Cartilha & $\begin{array}{l}\text { Medida Provisória } 936 \text { de 2020. Disponível em: } \\
\text { http://www.planalto.gov.br/ccivil_03/_ato2019- } \\
\text { 2022/2020/mpv/mpv936.htm.Acesso em 18/12/2020. Medida Provisória } 959 \\
\text { de } 29 \text { de Abril de 2020. Disponível em: } \\
\text { http://www.planalto.gov.br/ccivil_03/_ato2019-2022/2020/mpv/mpv959.htm. } \\
\text { Acesso em 18/12/2020. Portaria 10.486 de 22 de Abril de 2020. Disponível } \\
\text { em: https://www.in.gov.br/en/web/dou/-/portaria-n-10.486-de-22-de-abril-de- } \\
\text { 2020-253754485. Acesso em:18/12/2020. }\end{array}$ \\
\hline $\begin{array}{l}\text { FGTS: Conheça } \\
\text { algumas situações } \\
\text { que autorizam o } \\
\text { saque }\end{array}$ & Cartilha & $\begin{array}{l}\text { Medida Provisória } 946 \text { de 2020. Disponível em: } \\
\text { https://www.in.gov.br/en/web/dou/-/medida-provisoria-n-946-de-7-de-abril- } \\
\text { de-2020-251562794. Acesso em: 18/12/2020. }\end{array}$ \\
\hline $\begin{array}{l}\text { Manutenção da } \\
\text { Qualidade de } \\
\text { Segurado }\end{array}$ & Cartilha & $\begin{array}{l}\text { Lei } 8.213 \text { de } 24 \text { de Julho de 1981. Disponível em: } \\
\text { http://www.normaslegais.com.br/legislacao/trabalhista/lei8213.htm. Acesso } \\
\text { em 18/12/2020. }\end{array}$ \\
\hline $\begin{array}{l}\text { Direitos } \\
\text { Trabalhistas nas } \\
\text { Diferentes } \\
\text { Modalidades de } \\
\text { Rescisão } \\
\end{array}$ & Cartilha & $\begin{array}{l}\text { Lei } 5.452 \text { de } 1^{\circ} \text { de Maio de } 1943 \text {. Disponível em: } \\
\text { http://www.planalto.gov.br/ccivil_03/decreto-lei/del5452.htm. Acesso em } \\
\text { 18/12/2020. }\end{array}$ \\
\hline $\begin{array}{l}\text { Seguro } \\
\text { desemprego e } \\
\text { regras para } \\
\text { Recebimento }\end{array}$ & Cartilha & $\begin{array}{l}\text { Ministério do Trabalho lança Seguro Desemprego pela internet. Disponível } \\
\text { em: https://empregabrasil.mte.gov.br/545/ministerio-do-trabalho-lanca-o- } \\
\text { seguro-desemprego-pela-internet/. Acesso em 18/12/2020. Previdencia e } \\
\text { Trabalho. Governo do Brasil. Disponível em: www.gov.br/trabalho/pt-br. } \\
\text { Acesso em 18/12/2020. }\end{array}$ \\
\hline $\begin{array}{l}\text { Lei Aldir Blanc - } \\
\text { Lei } n^{\circ} 14.017 \text {, de } \\
29 \text { de Junho de } \\
2020\end{array}$ & Cartilha & $\begin{array}{l}\text { Lei n } 14.017 \text { de } 29 \text { de junho de } 2020 \text {. Disponível em: } \\
\text { https://www.in.gov.br/en/web/dou/-/lei-n-14.017-de-29-de-junho-de-2020- } \\
\text { 264166628. Acesso em 18/12/2020. }\end{array}$ \\
\hline $\begin{array}{l}\text { Ensino Remoto } \\
\text { Emergencial: } \\
\text { Orientações sobre } \\
\text { Direitos Autorais } \\
\text { e da Imagem }\end{array}$ & Cartilha & $\begin{array}{l}\text { Lei } 9.610 \text { de } 19 \text { de Fevereiro de 1998. Disponível em: } \\
\text { http://www.planalto.gov.br/ccivil_03/leis/19610.htm. Acesso em:22/12/2020 }\end{array}$ \\
\hline $\begin{array}{l}\text { Lei n } \text { n }^{14.023} \text { de } 6 \\
\text { de Fevereiro de } \\
2020 \text { : Prioriza } \\
\text { ações para } \\
\text { preservação da } \\
\text { saúde e vida dos } \\
\text { profissionais } \\
\text { essenciais no } \\
\text { combate à } \\
\text { pandemia; }\end{array}$ & Cartilha & $\begin{array}{l}\text { Lei.14.023 de } 8 \text { de Julho de 2020. Disponível em: } \\
\text { https://www2.camara.leg.br/legin/fed/lei/2020/lei-14023-8-julho-2020- } \\
\text { 790401-norma-pl.html. Acesso em: 22/12/2020. }\end{array}$ \\
\hline $\begin{array}{l}\text { Prorrogação do } \\
\text { Auxílio } \\
\text { Emergencial }\end{array}$ & Cartilha & $\begin{array}{l}\text { Medida Provisória no 1000/2020. Disponível em: } \\
\text { http://www.planalto.gov.br/ccivil_03/_ato2019- } \\
\text { 2022/2020/Mpv/mpv1000.htm. Acesso em 18/12/2020. }\end{array}$ \\
\hline $\begin{array}{l}\text { Lei. } 14.020 \text { de } 6 \\
\text { de Julho de } 2020 \\
\text { e Decreto } \mathrm{n}^{\circ} \\
14.422 \text { de } 13 \text { de } \\
\text { Julho de } 2020 \\
\text { medidas } \\
\text { trabalhistas para o }\end{array}$ & Cartilha & $\begin{array}{l}\text { Lei } 14.020 \text { de } 6 \text { de Julho de } 2020 \text { e Decreto } 10.422 \text { de } 13 \text { de Julho de } 2020 \text {. } \\
\text { Disponível em: https://www.in.gov.br/en/web/dou/-/lei-n-14.020-de-6-de- } \\
\text { julho-de-2020-265386938. Acesso em 18/12/2020. }\end{array}$ \\
\hline
\end{tabular}




\begin{tabular}{|c|c|c|}
\hline $\begin{array}{l}\text { enfrentamento de } \\
\text { estado de } \\
\text { calamidade } \\
\text { pública }\end{array}$ & & \\
\hline $\begin{array}{l}\text { Lei } 14.044 \text { de } 24 \\
\text { de agosto de } \\
\text { 2020: conversão } \\
\text { da MP } 948 / 2020\end{array}$ & Infográfico & $\begin{array}{l}\text { Medida Provisória no } 948 \text { de 2020. Disponível em: } \\
\text { http://www.planalto.gov.br/ccivil_03/_Ato2019- } \\
\text { 2022/2020/Mpv/mpv948.htm.Acesso em:18/12/2020. Lei n } 14.044 \text { de } 24 \text { de } \\
\text { agosto de 2020. Acesso em 18/12/2020. Disponível em: } \\
\text { https://www.in.gov.br/en/web/dou/-/lei-n-14.044-de-19-de-agosto-de-2020- } \\
\text { 273220109. Acesso em 18/12/2020. }\end{array}$ \\
\hline $\begin{array}{l}\text { Atualização } \\
\text { Auxílio } \\
\text { emergencial- } \\
21 / 09\end{array}$ & Infográfico & $\begin{array}{l}\text { Lei } 13.892 \text { de } 2 \text { de Abril de 2020. Disponível em: } \\
\text { https://www.in.gov.br/en/web/dou/-/lei-n-13.982-de-2-de-abril-de-2020- } \\
\text { 250915958. Acesso em 18/12/2020. Decreto 10.316 de } 7 \text { de Abril de } 2020 \text {. } \\
\text { Disponível em: http://www.planalto.gov.br/ccivil_03/_ato2019- } \\
\text { 2022/2020/decreto/d10316.htm. Disponível em 18/12/2020. }\end{array}$ \\
\hline NOVO FIES & Cartilha & $\begin{array}{l}\text { A Lei número } 13.998 \text { de } 14 \text { de maio de 2020. Disponível } \\
\text { em:http://www.planalto.gov.br/ccivil_03/_ato2019- } \\
\text { 2022/2020/lei/L13998.htm. Acesso em 22/12/2020. }\end{array}$ \\
\hline $\begin{array}{l}\text { Regulamentação } \\
\text { da idade da mãe } \\
\text { adolescente para } \\
\text { recebimento do } \\
\text { auxílio } \\
\text { emergencial }\end{array}$ & Cartilha & $\begin{array}{l}\text { Decreto } \mathrm{n}^{\circ} 10.398 \text { de } 16 \text { de Junho de } 2020 \text {. Disponível em: } \\
\text { https://www.in.gov.br/en/web/dou/-/decreto-n-10.398-de-16-de-junho-de- } \\
\text { 2020-261925227. Acesso em: 22/12/2020. }\end{array}$ \\
\hline $\begin{array}{l}\text { Prorrogação do } \\
\text { Auxílio } \\
\text { Emergencial }\end{array}$ & Cartilha & $\begin{array}{l}\text { Medida Provisória no 1000/2020. Disponível em: } \\
\text { http://www.planalto.gov.br/ccivil_03/_ato2019- } \\
\text { 2022/2020/Mpv/mpv1000.htm. Acesso em 18/12/2020. }\end{array}$ \\
\hline $\begin{array}{l}\text { Portaria conjunta } \\
n^{\circ} 20 \text { de } 18 \text { de } \\
\text { Junho de } 2020- \\
\text { Parte } 1,2,3,4,5,6 \\
\text { e } 7\end{array}$ & $\begin{array}{l}\text { Infográfico } \\
\text { s e } \\
\text { cartilhas }\end{array}$ & $\begin{array}{l}\text { Portaria Conjunta } \mathrm{n}^{\circ} 20 \text { de } 18 \text { de Junho de 2020. Disponível em: } \\
\text { https://www.in.gov.br/en/web/dou/-/portaria-conjunta-n-20-de-18-de-junho- } \\
\text { de-2020-262408085. Acesso em 22/12/2020. }\end{array}$ \\
\hline $\begin{array}{l}\text { Medida } \\
\text { Provisória } 927 \text { de } \\
22 \text { de Março de } \\
2020\end{array}$ & Vídeo & $\begin{array}{l}\text { Medida Provisória } 927 \text { de } 22 \text { de Março de 2020. Disponível em: } \\
\text { http://www.planalto.gov.br/ccivil_03/_ato2019-2022/2020/mpv/mpv927.htm. } \\
\text { Acesso em 18/12/2020. }\end{array}$ \\
\hline $\begin{array}{l}\text { Lei } n^{\circ} 23.643 \text { de } \\
22 \text { de Maio de } \\
2020 \text { do Estado } \\
\text { de Minas Gerais; }\end{array}$ & Vídeo & $\begin{array}{l}\text { Lei Estadual } \mathrm{n}^{\circ} 23.643 \text { de } 22 \text { de Maio de 2020. Disponível em: } \\
\text { https://www.editoraroncarati.com.br/v2/Diario-Oficial/Diario-Oficial/LEI- } \\
\text { ESTADUAL-MG-N\%C2\%BA-23-643-DE-22-05-2020.html. Acesso em } \\
\text { 22/12/2020. }\end{array}$ \\
\hline $\begin{array}{l}\text { Portaria } 16.655 \text { de } \\
14 \text { de Julho de } \\
2020\end{array}$ & Cartilha & $\begin{array}{l}\text { Portaria } \mathrm{n}^{\mathrm{o}} \text { 16.655, de } 14 \text { de Julho de 2020. Disponível em: } \\
\text { https://www.in.gov.br/en/web/dou/-/portaria-n-16.655-de-14-de-julho-de- } \\
\text { 2020-266640831. Acesso em 18/12/2020. }\end{array}$ \\
\hline
\end{tabular}
Fonte: Os autores.

O Quadro 2, a seguir, resume todo o alcance dos conteúdos postados nas mídias sociais, com o registro, em números, das visualizações e reações do público. 
Quadro 2. Resumo de todo o alcance dos conteúdos postados nas mídias sociais, com o registro, em números, das visualizações e reações do público.

\begin{tabular}{|c|c|c|c|c|}
\hline \multirow{2}{*}{ Publicação } & \multicolumn{2}{|c|}{ Facebook } & \multicolumn{2}{|c|}{ Instagran } \\
\hline & Alcance & Impressões & Alcance & Impressões \\
\hline $\begin{array}{c}\text { Lei } \mathrm{n}^{\circ} \text { 13.982: você conhece o auxílio } \\
\text { emergencial? }\end{array}$ & 1682 & 1947 & 1547 & 1812 \\
\hline Benefício de prestação continuada - LOAS & 1023 & 1162 & 971 & 1223 \\
\hline $\begin{array}{l}\text { Medidas trabalhistas para enfrentamento do } \\
\text { estado de calamidade pública - Parte } 1\end{array}$ & 1071 & 1205 & 1229 & 1333 \\
\hline $\begin{array}{l}\text { Medidas trabalhistas para enfrentamento do } \\
\text { estado de calamidade pública - Parte } 2\end{array}$ & 1168 & 1384 & 886 & 988 \\
\hline FGTS: situações que autorizam o saque & 1024 & 1149 & 804 & 888 \\
\hline $\begin{array}{l}\text { Manutenção da qualidade de segurado: período } \\
\text { de graça no Regime Geral de Previdência Social }\end{array}$ & 873 & 1003 & 551 & 691 \\
\hline $\begin{array}{c}\text { Direitos trabalhistas nas diversas modalidades de } \\
\text { rescisão }\end{array}$ & 826 & 930 & 699 & 778 \\
\hline $\begin{array}{l}\text { Seguro desemprego: conheça as regras para o } \\
\text { recebimento }\end{array}$ & 743 & 938 & 516 & 562 \\
\hline $\begin{array}{l}\text { Lei Aldir Blanc: Lei no } 14.017 \text { de } 29 \text { de junho de } \\
\qquad 2020\end{array}$ & 583 & 670 & 593 & 658 \\
\hline 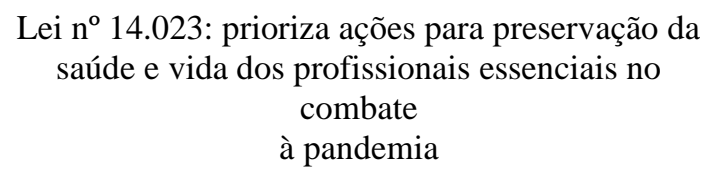 & 209 & 267 & 690 & 779 \\
\hline Prorrogação do auxílio emergencial & 1599 & 1848 & 1154 & 1465 \\
\hline $\begin{array}{l}\text { Lei } \mathrm{n}^{\circ} 14.020 \text { e Decreto } \mathrm{n}^{\circ} 14.422 \text { : medidas } \\
\text { trabalhistas para o enfrentamento do estado de } \\
\text { calamidade pública }\end{array}$ & 753 & 886 & 792 & 869 \\
\hline $\begin{array}{l}\text { Lei n } n^{\circ} 14.046 \text { de } 24 \text { de agosto de } 2020 \text { : } \\
\text { conversão da MP 948/2020 }\end{array}$ & 653 & 714 & 674 & 746 \\
\hline Atualização - auxílio emergencial - 21/09 & 721 & 803 & 1098 & 1169 \\
\hline Novo FIES & 1430 & 1607 & 674 & 861 \\
\hline $\begin{array}{l}\text { Regulamentação da idade da mãe adolescente } \\
\text { para recebimento do auxílio emergencial Decreto } \\
n^{\circ} 10.398 / 2020\end{array}$ & 34 & 67 & 126 & 166 \\
\hline  & 91 & 110 & 107 & 129 \\
\hline $\begin{array}{c}\text { Portaria conjunta } \mathrm{n}^{\circ} 20 \text { de } 18 \text { de junho de } 2020 \\
\text { Parte } 1\end{array}$ & 810 & 1015 & 627 & 677 \\
\hline $\begin{array}{c}\text { Portaria conjunta } \mathrm{n}^{\circ} 20 \text { de } 18 \text { de junho de } 2020 \\
\text { Parte } 2\end{array}$ & 674 & 856 & 807 & 911 \\
\hline
\end{tabular}




\begin{tabular}{|c|c|c|c|c|}
\hline $\begin{array}{c}\text { Portaria conjunta } \mathrm{n}^{\circ} 20 \text { de } 18 \text { de junho de } 2020 \\
\text { Parte } 3\end{array}$ & 38 & 66 & 706 & 765 \\
\hline $\begin{array}{c}\text { Portaria conjunta } \mathrm{n}^{\circ} 20 \text { de } 18 \text { de junho de } 2020 \\
\text { Parte } 4\end{array}$ & 620 & 717 & 398 & 435 \\
\hline $\begin{array}{c}\text { Portaria conjunta } \mathrm{n}^{\circ} 20 \text { de } 18 \text { de junho de } 2020 \\
\text { Parte } 5\end{array}$ & 665 & 751 & 816 & 863 \\
\hline $\begin{array}{c}\text { Portaria conjunta } \mathrm{n}^{\circ} 20 \text { de } 18 \text { de junho de } 2020 \\
\text { Parte } 6\end{array}$ & 1010 & 1115 & 850 & 917 \\
\hline $\begin{array}{c}\text { Portaria conjunta } \mathrm{n}^{\circ} 20 \text { de } 18 \text { de junho de } 2020 \\
\text { Parte } 7\end{array}$ & 446 & 487 & 695 & 760 \\
\hline Vídeo da Medida Provisória 927 & 14 & 35 & 126 & 170 \\
\hline $\begin{array}{c}\text { Vídeo da Lei } \mathrm{n}^{\circ} 23.643 \text { de 22/05/2020 do } \\
\text { Estado de Minas Gerais }\end{array}$ & 1000 & 1137 & 789 & 991 \\
\hline 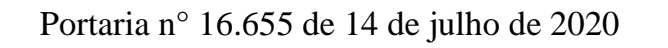 & 125 & 157 & 114 & 151 \\
\hline
\end{tabular}

Fonte: Os autores.

\section{DISCUSSÃO}

Ao abordar os resultados do projeto de extensão "Legislação Acessível em Tempos de Pandemia", é importante dividi-los em duas categorias: a primeira referente aos resultados da participação dos discentes e a segunda relativa aos benefícios das ações para a sociedade.

Assim, inicialmente, destaca-se a relevância de tal experiência para a formação e desenvolvimento dos estudantes envolvidos, haja vista que se constituiu em importante oportunidade para se conscientizarem e desenvolverem seu papel de agente de transformação social, por meio da discussão de temas extremamente atuais e de importância nacional, ajudando pessoas neste delicado momento da história do país e do mundo.

Outrossim, as práticas propostas pelo referido projeto priorizaram o protagonismo dos discentes e a experiência com o fazer com vistas à construção de sua autonomia e postura crítica e reflexiva.

A socialização do conhecimento, por seu turno, pode contribuir para o aumento do sentimento de pertencimento e autoestima desses estudantes, possibilitando reconhecerem-se como membros de uma coletividade para qual sua participação ativa e crítica é de grande relevância. 
Destarte, as ações propostas neste projeto de extensão pautaram-se no trabalho em equipe e cooperativo, envolvendo estudantes de diferentes cursos da instituição, favorecendo, portanto, a interação entre os alunos, com oportunidades de aprendizagem conjunta, contribuindo para o desenvolvimento da alteridade e solidariedade.

Neste contexto, para Bertrand (2001), por meio do diálogo os estudantes desenvolvem uma visão crítica acerca de seus conhecimentos. Igualmente, para Freire (1967), o diálogo está intimamente ligado à criticidade.

No que tange aos benefícios para a comunidade, destaca-se a relevância de ações que objetivem levar à sociedade informações acerca da legislação vigente. Assim, por meio da conscientização da população acerca das normas que regulam a estrutura social, sobretudo aquelas destinadas ao enfrentamento do estado de calamidade pública que se apresenta atualmente, acredita-se que os cidadãos serão mais conhecedores de seus direitos e obrigações e, com isso, a sociedade poderá tornar-se mais justa e organizada neste momento de crise.

Nessa perspectiva, segundo Brochado (2006) " [...] o direito deixa de ser um tema de juristas, advogados, autoridades; ele, enfim, passa a ser um tema de interesse de toda a coletividade, de seus destinatários finais".

\section{CONSIDERAÇÕES FINAIS}

O projeto "Legislação Acessível em Tempos de Pandemia" permitiu uma maior aproximação do Instituto Federal do Sudeste de Minas Gerais - Campus Rio Pomba com a população da cidade de Rio Pomba - MG e região, além de favorecer significativamente para a formação pessoal e profissional dos alunos e professores envolvidos no projeto.

A partir do retorno do público, com curtidas, compartilhamentos, perguntas e comentários, foi percebido que a estratégia utilizada pelo projeto alcançou seu objetivo. Assim, é relevante ressaltar que a utilização de materiais didáticos com fácil acesso, linguagem acessível e com uma arte visual chamativa, como proposto no projeto, proporciona uma aprendizagem significativa, facilitando a democratização do conhecimento jurídico, possibilitando a interação da população com a esfera jurídica e o exercício de seus direitos e deveres, contribuindo para o exercício pleno da cidadania.

Depreende-se da experiência que é indispensável o desenvolvimento de ações que envolvam educação jurídica popular, buscando a democratização do conhecimento 
jurídico, possibilitando construir uma sociedade justa e igualitária, onde todos os cidadãos possam ter amplo acesso à justiça.

\title{
NOTAS
}

\author{
${ }^{1}$ Legislação Acessível em Tempos de Pandemia. Recuperado de: \\ https://drive.google.com/file/d/1rhty_85RylhZiAhCD_6onlO68flaAAdP/view. \\ ${ }^{2}$ Portal da Legislação do Governo Federal. Recuperado de: \\ http://www4.planalto.gov.br/legislacao/.
}

\section{REFERÊNCIAS}

ALVES, F. D. N.; SILVA, D. G.; FERREIRA, A. de M.; Lima, L. Tecnologias Digitais na Docência: A Extensão Universitária como Lócus Formativo. Extensão em Ação [Online] 2020; [acesso em 02 jun. 2021]; v. 20, nº 2, jul-dez 2020. Disponível em http://www.periodicos.ufc.br/extensaoemacao/article/view/42561.

BERTRAND, Y. Teorias contemporâneas da educação. $2^{\mathrm{a}}$. ed. Lisboa: Horizontes pedagógicos, 2001.

BROCHADO, M. Pedagogia jurídica para o cidadão: formação da consciência jurídica a partir de uma compreensão ética do Direito. Revista da Faculdade de Direito, Belo Horizonte, v. 48, p. 159-188, 2006.

DESLANDES M.S.S., ARANTES, A.R. A extensão universitária como meio de transformação social e profissional. Sinapse Múltipla [Online]. 2017 [acesso em 05 dez. 2020]; v. 6 n. 2, 179-183. Disponível em: $<$ http://periodicos.pucminas.br/index.php/sinapsemultipla/article/view/16489.

FREIRE, P. Educação como prática da liberdade. Rio de Janeiro: Paz e Terra, 1967.

GURGEL, A. M. SANTOS, C. C. S.; ALVES, K. P. S; ARAÚJO, J. M.; LEAL, V. S. Estratégias governamentais para a garantia do direito humano à alimentação adequada e saudável no enfrentamento à pandemia de Covid-19 no Brasil. Ciência \& Saúde Coletiva [online]. 2020, v. 25, n. 12 [Acessado 10 jun. 2021], pp. 4945-4956. Disponível em: https://www.cienciaesaudecoletiva.com.br/artigos/estrategiasgovernamentais-para-a-garantia-do-direito-humano-a-alimentacao-adequada-esaudavel-no-enfrentamento-a-pandemia-de-covid19-no-brasil/17778?id=17778.

LAMAS C. B. O.; MIRANDA P. R.; OLIVEIRA A. P. L. R. Aproximações entre educação jurídica e ensino médio integrado: proposta para uma formação cidadã e ética. Revista de Estudos e Pesquisas sobre Ensino Tecnológico (EDUCITEC) [Online]. 2018 [acesso em 01 jun. 2021]; v. 4 n. 08, 421-439. Disponível em https://sistemascmc.ifam.edu.br/educitec/index.php/educitec/article/view/569. 
ZAMBON, F. B.; ARAÚJO F. Cidadania em Contexto Escolar: Concepções e Práticas. III Jornada de didática. Desafios para docência e II seminário de pesquisa do

\section{CEMAD [Online]. 2014. [acesso em 01 jun. 2021], 177-189. Disponível em}

http://www.uel.br/eventos/jornadadidatica/pages/arquivos/III\%20Jornada\%20de\%20Di datica\%20-

\%20Desafios\%20para\%20a\%20Docencia\%20e\%20II\%20Seminario\%20de\%20Pesquis a\%20do\%20CEMAD/CIDADANIA\%20EM\%20CONTEXTO\%20ESCOLAR.pdf.

Recebido em: 03/01/2022

Aprovado em: 30/01/2022

Publicado em: 01/02/2022 